\title{
SPONSORSHIP RESEARCH: DRAWING ON THE PAST TO SHAPE THE FUTURE OF SPONSORSHIP
}

\author{
Margaret A. Johnston, The University of Queensland, UQ Business School, Australia
} George S. Spais, Hellenic Open University, Patra, Greece

\begin{abstract}
This study examines how scholarly research on sponsorship has evolved between 1980 and July 2012. While various scholars (e.g., Cornwell and Maignan 1998; Pope 1998; Walliser 2003) have documented the progress of sponsorship research previously, this review departs from existing perspectives and redirects the conversation in the sponsorship literature by focusing attention on the semantic relationships among sponsorship concepts and the ways in which they have changed over time. Using Leximancer text-analysis software, we explore the emergence and growth of ideas and topics in sponsorship research by undertaking a systematic analysis of ideological trends. The research objectives of this study are: (1) to identify the scholarly trends through an empirical assessment of research across the history of sponsorship; and (2) based on the trends identified, to shape the future of sponsorship research.
\end{abstract}

We collected titles and abstracts of articles in sponsorship presented in scholarly journals to July 2012. Guided by previous authors, we focused specifically on sourcing abstracts since abstracts encapsulate a concise summary of an article's core issues and are therefore lexically dense (Cretchley et al. 2010). We sourced abstracts for our analyses from multiple databases (e.g., ISI Web of Science, Scopus, EconPapers (RePEc), PsycINFO and GoogleScholar) and from over 150 marketing journals. We included abstracts from journals in languages other than English where English translations of the abstract were available electronically (Walliser 2003). In total, we collected 804 articles published across 144 scholarly journals. Next, we created subsets of the data in 10-year periods (1980-1989, 1990-1999, and 2000-2009), and one for 2010-2012. Using Leximancer software (Version 4.0), we produced a set of concept maps and reports showing semantic structures across the history of sponsorship for each of the four periods (see Smith and Humphreys 2006).

The concept map of the entire corpus of abstracts revealed a core set of concepts that are recurrent and quite evenly distributed throughout the history of sponsorship. Sponsorship, marketing, objectives, value, strategy, companies, important, and key are concepts central to sponsorship's intellectual identity. We identified two primal opposing but complementary forces around sponsorship measurement (e.g., consumers, awareness, brand, effects, image, impact, media, advertising) and sponsorship management (e.g., industry, benefits, rights, business, organizations, management, development, financial). Based on examination of the prominent concepts within each period, we defined the 1980s as the Intellectual Era (television, important, business, benefits, and advertising); the 1990s as the Ambushing Era (objectives, ambush, support, major, and corporate); the 2000s as the Consumer Era (products, financial, media, role, and market); and as the 2010s as the Relationships Era (professional, team, relationship, social and value).

In the decade 2010-2019, we expect to observe the development and empirical exploration of more managerially focused models of sponsorship that center on better understanding the development of sponsorship strategy and the extraction of value from sponsorship investment. Going forward, the integration of social media as a sponsorship-marketing tool could also define a new era of research. In brief, adding a new data set to earlier reflections on sponsorship deepens our understanding of the role that key concepts and their inter-relationships have played in shaping sponsorship scholarship to date. We strongly believe the current study lends a high level of credibility to our insights about sponsorship's past that can richly inform discussions about the future directions of sponsorship research. 